\title{
Integration of a socio-economic dimension to the prioritization of combating erosion applications: Antalya case study
}

\section{Authors Info}

\section{U. COŞGUN}

Department of Forest Engineering, Faculty of Forestry, Karabük University, Karabuk, 78100,Turkey

*Corresponding Author Email : ufukcoşgun@karabuk.edu.tr

Key words

Erosion Desertification,

Factor Analyses,

Multivariate analyses techniques,

\section{Publication Info}

Paper received : 16.08 .2016

Revised received : 24.06.2017

Accepted : 28.06.2017

\section{Abstract}

Aim: The objective of this study was to prioritize the regions in Antalya by taking into consideration the factors causing erosion and desertification.

Methodology: Materials used in the study include technical factors, such as soil depth, inclination spectrum, land use types and forest stand productivity, as well asvarious socio-economic factors like proportion of forest village populations, coverage of agricultural fields, number of ovine and cattle, coverage of pastures, intensity of grazing, socio-economic development values, educational level, employment state and forest crimes. The data set obtained from those technical and socio-economic materials was assessed using multivariate analyses techniques.

Results: The towns in Antalya have been sequenced according the priorities in erosion prevention studies and the approach to be taken on the appropriate erosion prevention investment was assessed by evaluating how the resources could rationally be used and which regions should be prioritized.

Interpretation: The technical and socio-economic indicators established by this study have resulted in the identification of factors that can be used to select the priority areas. Based on the districts of Antalya, Gazipaşa, Kumluca, Finike and Gündoğmuş districts are placed in one group within the scope of the study, in order to prioritize the areas of activity for combating desertification and erosion. The districts of Elmalı and Serik are placed in another group, while the districts of Kaş, Manavgat and Korkuteli are in yet another group. The Central District of Antalya comprise a group of its own. These groups should be taken into consideration when implementing activities for the rational use of resources.

\section{Socio and Economic Indicators
(28 factors) $\longleftrightarrow \begin{gathered}\text { Areas Indicators } \\ \text { (7 factors) }\end{gathered} \longleftrightarrow \begin{gathered}\text { Desertification and Erosion Indicators } \\ \text { (22 factors) }\end{gathered}$ (28 factors)}

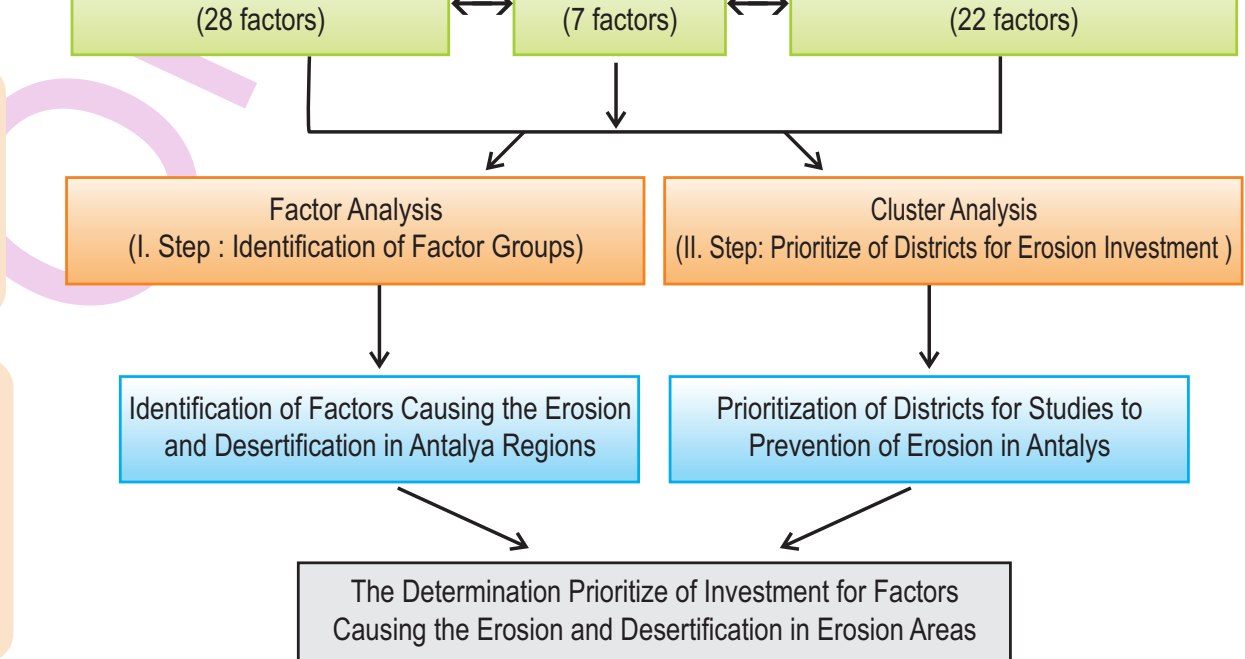




\section{Introduction}

Each year, 24 billion tons of topsoil is lost and six billion hectares of land becomes desertified for various reasons, of which erosion is the most prominent. This brings with it a financial loss to the world of more than 42 billion USD and the process directly threatens 1.2 billion people in 110 countries. About135 million people are at risk and 10 million people are becoming ecological migrants, as they leave desertified regions. Over 2.6 billion people, whose livelihood depends on the land, share the same fate (Orhan, 2011).

The regions at the highest risk of desertification are in North Africa, Middle East, Australia, South Western China and the western South America. These regions are currently combating a significant amount of desertification. The Mediterranean Region and tropical and subtropical steppe ecosystems, as well as having a lower level of shore and pasture area, are at a significant risk at the global scale(Núñez et al., 2010).

Soil loss is an important variable used in forest management planning with the sustainability of multiple values (Mısır, et al., 2007). Soil erosion, besides having significant impact on the productivity of cultivated land; also adversely affects chemical, physical and biological functions of soil leading to eutrophication of surface water resources and environmental pollution (Sharda et al, 2013).

According to the World Convention to Combat Desertification, desertification is defined as "soillosing its natural qualities, or in short, soil erosion, in regions of drought, semi-arid or regions receiving low rainfall, due to the effects of various factors such as climate change and human factors." According to this definition, one third of the world is at risk of desertification. The reasons for increasing desertification in Turkey are reported to be: Soil erosion; excessive degradation of pastures; deforestation; land misuse and mismanagement; v) desertification of land, and vi) drought (Orhan, 2011)

A review of the climate, topography, geology, hydrology, vegetation and land suitable and not suitable for cultivation, characteristic of pastures and forest areas of Turkey, together with an assessment of the impact of population, shows that Turkey is at risk of desertification as a result of the interaction between nature and humans (Anonymous, 2005).

The climate of Turkey, which is, in general, within the greater Mediterranean climate region that is dominant in the western landmass of the subtropical zone, is as a result of the Basra low pressure seasonal relocation that comprises the frontal depression caused by the North-eastern Atlantic and Mediterranean and the subtropical anticyclone and monsoon low pressure of the Middle East (Atalay, 2002).

There are these main reasons for desertification in Turkey viz. natural causes; technical reasons and socio-economic, administrative and legal reasons. The natural reasons are: soil erosion; water and wind erosion; dune activity; reduction in the quality of soil fertility, as the plant nutrient elements of soil are leached from the top soil or by washout and environmental changes (Anonymous, 2013). The technical reasons are: deforestation (destruction or extinction of forest areas due to fire, logging-settlements, illegal or unregistered logging and excessive grazing); incorrect, irregular, uncontrolled, untimely and excessive grazing in pastures, especially those in located on slopes; the hydrogeological structure or hydrological cycle being effected by artificial roads; Stubble burning; The inappropriate management of agricultural soil and exhaustion of soil; unregulated irrigation of farming land leading to the continued impact of high ground water; misuse of agricultural and forest areas (cementing of soil); problems such as the saltification of agricultural land and alkalinisation regarding desertification and acidity; soil pollution; physical destruction of the land; unregulated management of the agricultural and forest ecosystems or the misuse of land, or the wrongful use of agricultural, pasture and forest areas (agriculture in forest areas, agricultural use of pastures, use of forest areas as pastures, etc. and to prevent misuselack of regulation).

The socio-economic, administrative and legal reasons are: problems resulting from legislation; migration; lack of education. Within these main headings, the socio-economic and legal reasons, which can be referred to as sub-headings and that may contribute to the desertification in Turkey due to the lack of implementation of social, economic and legal regulations, are: unclear distribution of land ownership and high number of small enterprises; insufficient initiatives for collective land; taking no precautions for land that is leased or used for share cropping; lack of awareness of soil protection and education; lack of regulatory laws for the use and protection of soil and water; lack of restructuring of legal and administrative regulations, lack of necessary legislation, lack of sufficient legislative practices, or coordination between regulations; and rural poverty and migration(Anonymous, 2013).

International studies have attempted to determine the effects of desertification. Potential desertification variables are determined by evaluating the impact of possible environmental effects (Núñez et al., 2010). As the quality of the areas useis affected by many complicated factors, several suggestions recommend the separation of the different ecosystems, using a variety of indicators (Heijungs et al. 1992; Steen and Ryding 1993; Blonk et al. 1997; Cowell and Clift 2000; Mattsson et al. 2000).These approaches enable a variety of technical indicators to be determined for the identification of potential desertification.

With regard to the quality of the land use and land degradation, it is more necessary to consider the developmental of activities rather than the characteristics of the land (Guinée et al., 2001; Mattsson et al., 2000; Milài Canals et al,. 2007).This 


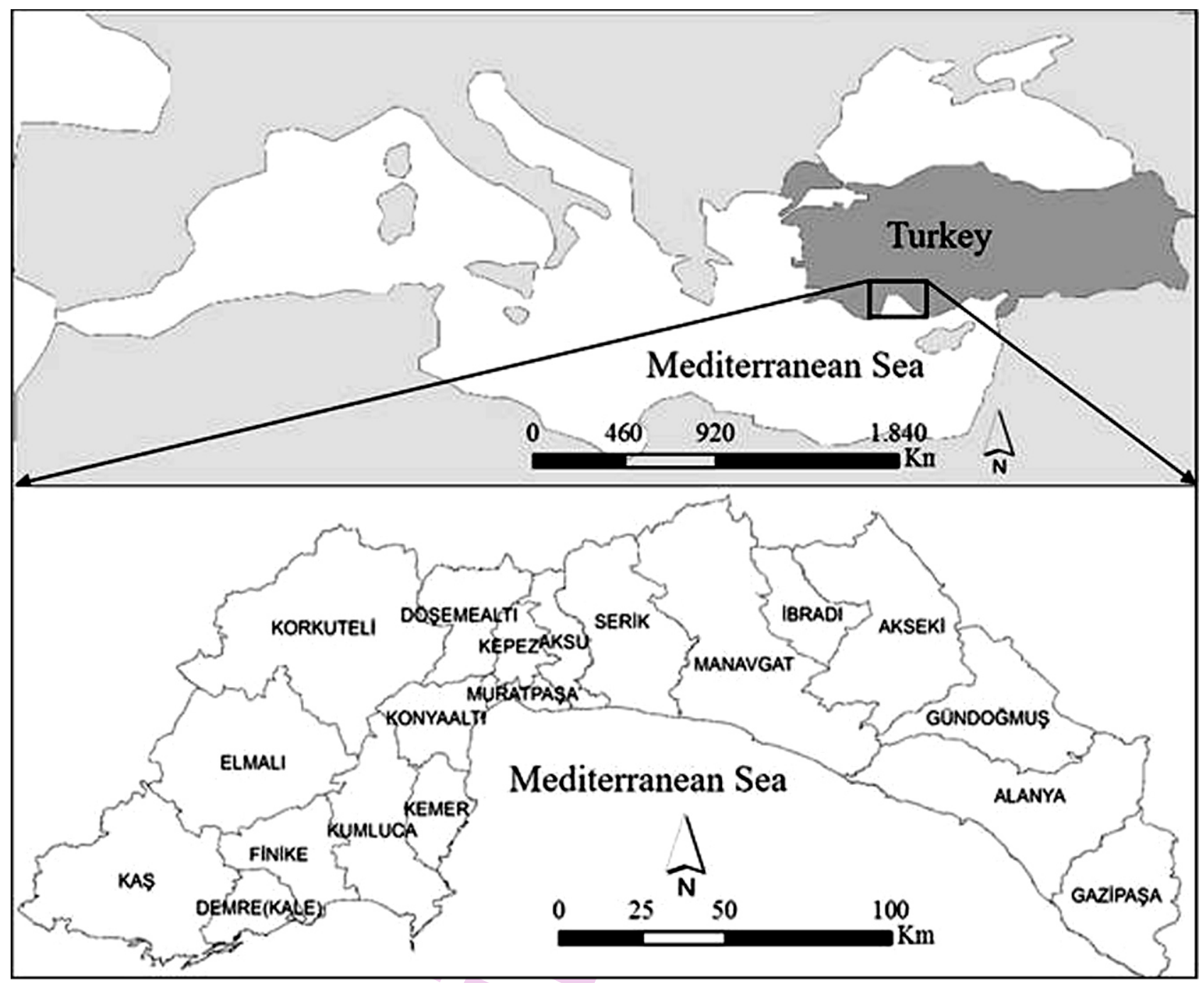

Fig. 1 : Study area

emphasizes the importance of human activity and consequently, the need to consider the effects of human activities on desertification. In addition to the various ecosystems, it can be seen that the socio-economic structure has an impact on the use of both land and soil quality. Therefore, in addition to technical reasons, the socio-economic reasons that lead to desertification are also a part of this study. Desertification indicators are organized according to the three dimensions of sustainable development. These are: environment (biophysical areas), economy and social structure (MIMAM, 2006).Worldwide, one of the main factors leading to desertification, which affects ecosystem functions and structures, are forest fires. An example of a study, which aims to categorize desertification and erosion sensitivity, only takes into consideration the technical reasons(Coşgunand Aydın, 2008).Activities to prevent desertification and erosion are laborintensive and require resources. Hence, the rational use of resources is necessary to prevent erosion and desertification. In order to use resources rationally, the erosion and desertification sensitive areas should be identified and prioritizedin terms of planning and investment.

The scope of the study is the province of Antalya and its districts (Figure 1). The aim of the study is to provide prioritization for the areas, according to technical and socio-economic factors that lead to erosion and desertification.

\section{Materials and Methods}

The materials of the study comprise several socioeconomic indicators that focus on the technical and human factors leading to erosion in the districts of Antalya (Table 1). The technical and socio-economic materials were analyzed using multiple quantitative analyses, principle component analysis, factor analysis and cluster analysis methods. 
Table 1 : Socio-economic and erosion and desertification indicators

\begin{tabular}{ll}
\hline Variables & Variable numbers \\
\hline Socio and economic indicators & 28 \\
Areas Indicators & 7 \\
Desertification and Erosion Indicators & 22 \\
Total & 57 \\
\hline
\end{tabular}

A number of socio-economic indicators were determined for this study based on Development Ranking of Provinces and Districts in Turkey. Local indicators reflecting forest villages were added to these indicators. In addition to indicators, such as population (population density, average household size, population growth rate and urbanization rate), education (literacy, percentage of primary school, secondary school and university graduates and female literacy rate) and employment (unemployment rate, and the proportion of the population working in various sectors), indicators that may lead to desertification and erosion that may arise from activities in forest areas were also included. Evasion of forest crimes, illegal logging and existing average burning forest assets (10-year average value) constitute some of these indicators (FAO, 2006). Indicators, such as existing marginal dry farming areas, grazing intensity in the district, livestock assets per household, existing damaged forest areas, dry and irrigated absolute farming areas and pasturing areas, were included in the assessment, as natural cause indicators that may result in desertification and erosion. The indicators relating to technical reasonsthat were included in the study include: soil depth status of the land, the amount of land with water erosion of varying severity, sloping land of varying degrees andvalues of land area according tousage types.

\section{Results and Discussion}

Factors that have an impact on Desertification and Erosion: A total of 57 indicators that have an impact on desertification and erosion at the district level for the province of Antalya were identified. The factors that may be effect on desertification and erosion were compiled into five groups (Table 2).

The Slope Factor group consists of the Amount of High Level Slope Land of Districts and Amount of Medium Level Slope Land of Districts indicators (Table 2). The second factor group, i.e.,Demographic Factor group comprises the indicators for Population Density and the Population of Districts and the Amount of V, Grade Land of Districts indicators, used for grading the use of the land. The quantity of old and Barren Land in the Districts indicator is a standalone factor. In the third factor group, referred to as the Factor for the Existence of Old and Barren Land. The Rate of Dependency of Population and Average Household Size indicators make up the fourth factor group, viz. Social development factor the rate of population dependency, one of the indicators for the level of development of a country or their provinces, is defined as the number of unemployed people (aged 0-14 and 65+) of a country, who are dependent for every 100 employed people (aged 15-65) (Zaim, 1992). The fifth factor group the Desertification Factor comprises the Amount of VI. Grade Land of Districts indicator with the land use grading and the Amount of Steep Slope Land of Districts indicators, together with the Amount of Burnt Forest Land indicators. The indicators in this group include the indicators to be considered for land desertification (MIMAM, 2005).

Categorisation of Districts According to Desertification and Erosion Indicators : A cluster analysis was used to determine the priority districts of Antalya, where desertification and erosion prevention studies would be conducted with the support of the natural, technical and socio-economic indicators which are effective on desertification and erosion. The 57 indicators identified by the study were used in the cluster analysis.

To assess the indicators effective on desertification and erosion, by means of the cluster analysis, the districts of Antalya were divided into four groups. One group included the districts of Gazipaşa, Kumluca, Finike and Gündoğmuş; another included Elmalı and Serik; a third comprised Kaş, Manavgat and Korkuteli and the last group comprised the central district of Antalya (Fig. 2).

Many indicators are used to determine desertification and erosion (Núñez et al., 2010), and inevitably take into consideration human activities. In Turkey, the first ranked factor leading to damage of land is the human factor. The damage is natural environment due to human activity quickly leads to erosion and desertification. It is possible to rehabilitate these areas with good planning and efficient and effective use of resources. Land use conversion can affect natural ecological processes such as surface run off and erosion. Therefore, it has potential to change soil stability (Korkanç et al, 2008). The rehabilitation of the areas that are facing the threat of desertification and erosionis labor-intensive and requires a significant investment of funds in Turkey, Reforestation and erosion management is one of the activities conducted within this scope; however, it cannot be said that sufficient funds are allocated for this. Therefore, it is necessary to prioritize areas in which the activities should be carried out. There are areas in districts of Antalya that require action for combating desertification and erosion prevention. However, it has not yet been determined which of these actions should be taken, and in which areas. The decisions for these actions, which are implemented by the General Directorate of Forestry, are taken centrally after getting opinions at the local level but priorities have not yet been determined. Hence the current study is of particular significance, as it will provide guidance to the decisions makers at the local level, the General Directorate of Forestry and the General Directorate of Combating Desertification and Erosion. 
Table 2: Factors groups for socio-economic and desertification and erosion indicators

\begin{tabular}{|c|c|c|c|c|c|}
\hline \multirow[t]{2}{*}{ Variables } & \multicolumn{5}{|c|}{ Factors } \\
\hline & 1 & 2 & 3 & 4 & 5 \\
\hline CKDIKEGM: (Amount of High Level Slope Land of Districts) & 0.892 & & & & \\
\hline ORTEGM: (Amount of Medium Level Slope Land of Districts) & 0.886 & & & & \\
\hline NUFYOGNL: (Population Density) & & 0.960 & & & \\
\hline VSNFARZ: (Amount of V. Grade Land of Districts) & & 0.951 & & & \\
\hline NUFUS: (Population of Districts) & & 0.939 & & & \\
\hline YASCORK: (Amount of Old and Barren Lands of Districts) & & & & & \\
\hline BAGÝMLÝ: (Rate of Dependency of Population) & & & & 0.963 & \\
\hline ORTHANE: (Average Household Size) & & & & 0.874 & \\
\hline VISNFARZ: (Amount of VI Grade Land of Districts) & & & & & 0.952 \\
\hline DIKEGM: (Amount of Steep Slope Land of Districts) & & & & & 0.925 \\
\hline YNGNALNORT: (Amount of Burnt Forest Land) & & & & & 0.895 \\
\hline
\end{tabular}
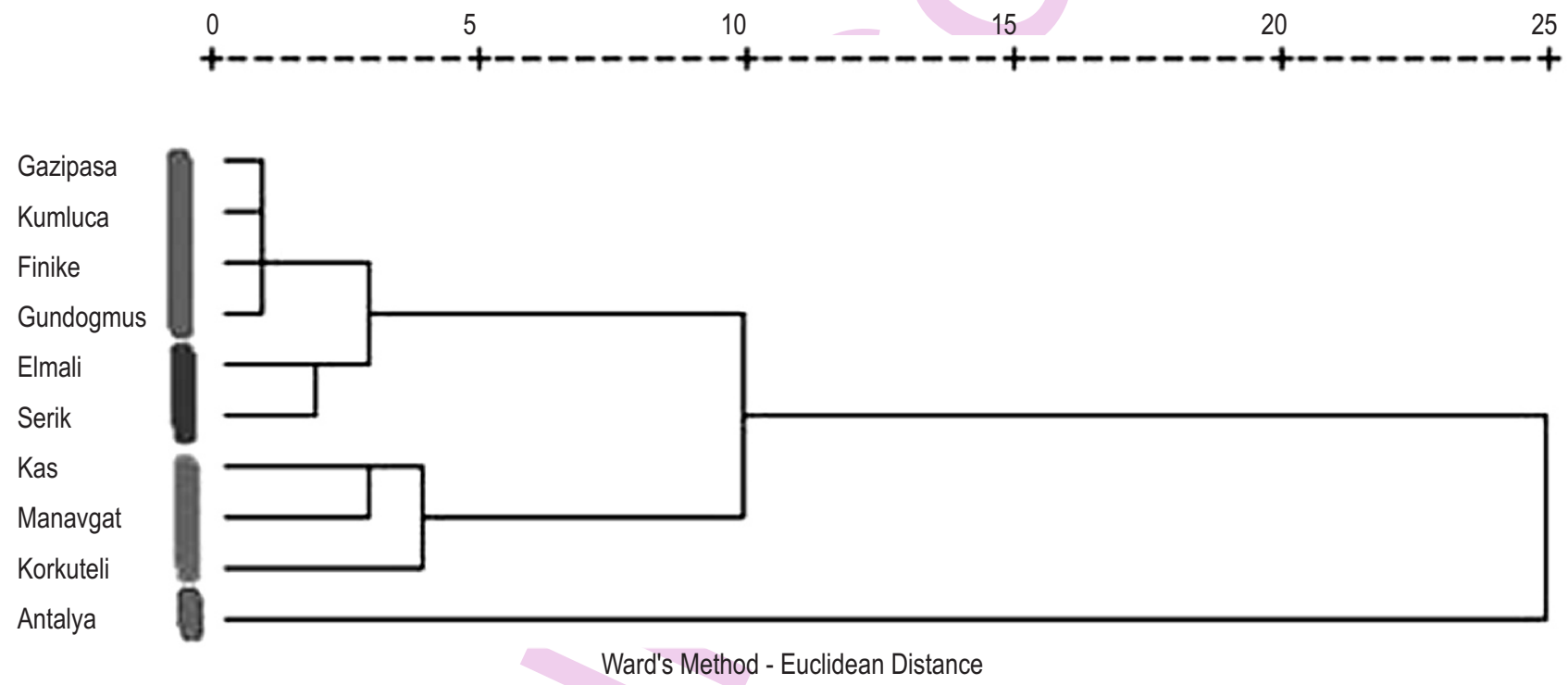

Fig. 2 : Cluster analysis for districts of Antalya

Meanwhile, there are national and international projects that are being implemented with the objective of combating desertification and erosion.

Some national projects, which have been or are being implemented in Turkey are:i) Ankara-EşrefAkıncı Barracks Erosion Control Project, ii) Ankara-Gökçeyurt Erosion Training Project, iii) Çorum Çamdağ Tekçam Multi-Purpose Implementation Project, iv) Elazığ Ağın Erosion Control Project, v) Elazığ Keban Ağın Dam Reservoir Basin Erosion Control Project, vi) Tokat ReşadiyeMulti-Purpose Implementation Project, Examples of international projects are: i) Anatolian Water Basin Rehabilitation Project, ii) Çoruh River Basin Joint Basin Rehabilitation Project, iii) Eastern Anatolian Water Basin Rehabilitation Project, iv) Capacity Building for Sustainable
Management of Mountain Watersheds of Central Asia and Caucasus, v) Middle East Watershed Monitoring and Assessment Project. Examples of completed or continuing projects of the General Directorate of Forestry: i) Çoruh River Basin Rehabilitation Project, ii) Murat Basin Rehabilitation Project, and iii) Anatolian Water Basin Rehabilitation Project (Anonymous, 2016/a; 2016/b).

In these projects there are no indicators concerning which areas are of priority for the activities. For example, the basis of planning for the Murat Basin Rehabilitation Project is made on micro-watersheds. Implementation of these micro-watershed plans will be carried out at a later stage. This international project does not have any indicators for planning the priority microwatersheds, or planning to indicate which micro-watershed 
activity should start first. The plans for some micro watersheds to be implemented under the project should be queried, as to whether there is a real need for the planning. One such example is the Büyükdere Micro Watershed plan activity.

In this study, 57 natural, socio-economic and technical indicators, which were thought to be effective for combating desertification and erosion and can be obtained at the regional level, were can be seen that determining the impact of desertification is at least as important as determining priority areas of desertification and erosion (Núñez et al., 2010; Montserrat, 2010; Civit, 2009). A variety of techniques is used to evaluate the effects of desertification By using technical and socio-economic related factors, the priority areas in which to carry out these actions will be identified by establishing the areas higly affected by desertification. The ecological and social characterizes of arid and semi-arid land as socio economic famine, may lead to following; lack of food and nutrition, water deficiencies in settlement areas and agriculture; famine and death; unplanned increase of population; external debt and current account deficit (balance of payments); lack of raw materials and water in industry (Görücü, 2011). When the problems arising from the socio-economic needs are ascertained, it can be seen that determining the impact of desertification is at least as important as determining priority areas of desertification and erosion. The technical and socioeconomic indicators established by this study, have resulted in the identification of factors that can be used to select the priority areas. These factors are as follows: Slope factor; Demographic Factor; Existence of Old and Barren Land Factor; Social DevelopmentFactor; Desertification Factor.

With the support of these factors, the measures to be taken for combating desertification and erosion can be prioritized in other areas nationwide (with the support of variables comprising these factors). Planning and implementation activities can be carried out according to order of priority. In this way, available limited financial resources can be used judiciously.

Based on the districts of Antalya, Gazipaşa, Kumluca, Finike and Gündoğmuş districts are placed in one group within the scope of the study, in order to prioritize the areas of activity for combating desertification and erosion. The districts of Elmalı and Serikare placed in another group, while the districts of Kaş, Manavgat and Korkuteliare in yet another group. The Central District of Antalya comprisea group of its own. These groups should be taken into consideration when implementing activities for the rational use of resources.

\section{References}

Anonymous: National Action Plan for Combating Desertification in Turkey (2005).

Anonymous: National Strategy for Combating Desertification, 20132023, Ankara (2013).
Anonymous: General Directorate of Combating Desertification and Erosion, Projects, http://www.cem.gov.tr/erozyon/anasayfa/ collesmepagegrup/ accessed 20April 2016 (2016/a).

Anonymous: General Directorate of Forestry, Projects, http://www.ogm. gov.tr/Baskanliklar/DislliskilerEgitimveArastirma/Documents/P ROJELER.pdf/accessed 20April 2016 (2016/b).

Atalay, I.:Ecological Regions of Turkey, Ministry of Forestry Publications No: 163, Ankara (2002)

Blonk, H., E. Lindeijer and J. Broers: Towards a methodology for taking physical degradation of ecosystems into account in LCA. Inter. J. Life Cycle Assess., 2, 91-98 (1997).

Coşgun, U. and A.C. Aydın: The Assessment of Erosion and Potential for Desertification: Case Study of Antalya Province, Turkey, Natural Environment and Culture Region, Chapter Four, Cambridge Scholars Publishing, Newcastle, UK, pp. 77-92 (2008).

Cowell, S.J. and R. Clift: A methodology for assessing soil quantity and quality in life cycle assessment. J. Clean Prod., 8, 321-331, (2000).

FAO: Global Forest Resources Assessment (FRA 2005). Food and Agriculture Organization of the United Nations, http://www.fao. org/forestry/32085/en/ (last accessed date July 31, 2008) (2006).

Görücü, Ö.: Socio-Economic Dimensions in Management of Dry and Semi-Dry Land. Dry Land and Semi-Dry Land Management Workshop, Nevşehir (2011).

Guinée, J., M. Gorrée, R. Heijungs, G. Huppes, R. Kleijn, A. de Koning, L. van Oers, A.W. Sleeswijk, S. Suh and H.U. de Haes: An operational guide to the ISO-standards. Part 3: Scientific background. CML, Centre of Environmental Science, Leiden (2001).

Heijungs, R., J.B. Guinée, H. Huppes, R.M. Lankreijer, H.A. Udo de Haes, A.W. Sleeswijk, A.M.M. Ansems, P.G. Eggels, R. van Duin and H.P. Goede: Environmental Life Cycle Assessment of Products Guide and Backgrounds. Centre of Environmental Science (CML), Leiden (1992).

Korkanç, S.Y., N. Ozyuvacı and A. Hızal: Impacts of land use conversion on soil properties and soil erodibility. J. Environ. Biol., 29, 363370 (2008).

Núñez, M., B. Civit, P. Munoz, A.P. Arena, J. Rieradevall and A. Anton: Assesing potential desertification environmental impact in life cycle assesment. Int. J. Life Cycle Asse., 15, 67-78 (2010)

Mattsson, B., C. Cederberg and L. Blix: Agricultural land use in life cycle assessment (LCA): Case studies of three vegetable oil crops. J. Clean Prod., 8, 283-292 (2000).

Mısır, N., M. Mısır, U., Karahalil and H. Yavuz: Characterization of soil erosion and its implication to forest management. J. Environ. Biol., 28, 185-191 (2007)

Milà, I., L. Canals, C. Bauer, J. Depestele, A. Dubreuil, R. FreiermuthKnuchel, G. Gaillard, O. Michelsen, R. Müller-Wenk and B. Rydgren: Key elements in a framework for land use impact assessment in LCA. Int. J. Life CycleAsssess, 12, 5-15(2007).

MIMAM:Evaluaciónpreliminar de losimpactosen Españaporefectodelcam bioclimático. Ministerio de Medio Ambiente, Centro de Publicaciones, Secretaría General Técnica (2005).

MIMAM: III Informesobre el Programa de Acción Nacional contra la Desertificación, España. Ministerio de Medio Ambiente, Secretaría General para el Territorio y la Biodiversidad, Protección General para la Biodiversidad, Madrid (2006) 
Montserrat, N., B. Civit, P. Muñoz, A.P. Arena, J. Rieradevall and A. Antón: Assessing potential desertification environmental impact in life cycle assessment. Int. J. Life Cycle Asse., 15, 67-78, DOI 10.1007/s11367-009-0126-0) (2010).

Orhan, D.: What is Desertification? Dry Land and Semi-Dry Land Management Workshop, Nevşehir (2011).

Sharda, V.N., D. Mandal and P.R. Ojashi: Identification of soil erosion risk areas for conservation planning in different states of India. J. Environ. Biol., 34, 219-226 (2013)

Steen, B. and S.O. Ryding: The EPS enviro-accounting method. An application of environmental accounting for evaluation and valuation of environmental impact in product design. AFR, Stockholm (1993).

Zaim, S.: Labour Economics, Filiz Publications, Istanbul (1992). 